\title{
Sensitization of Eriochromeazurol-B in Presence of Cetyldimethylethylammonium Bromide for the Microdetermination of Some Lanthanides
}

\author{
ANIL B. ZADE ${ }^{*}$, PAWAN P. KALBENDE ${ }^{1}$, MAYURI S. UMEKAR ${ }^{1}$, AND GAJANAN $^{2}$ \\ W. BELSARE ${ }^{2}$ \\ ${ }^{1}$ Department of Chemistry, Laxminarayan Institute of Technology, R.T.M. Nagpur \\ University, Nagpur, MS-440010, India \\ ${ }^{2}$ Post Graduate Department of Chemistry, Shivaji Science College, Akola, MS-444001, \\ India \\ ab_zade18@yahoo.com
}

Received 06 August 2011; Accepted 26 October 2011

\begin{abstract}
Cetyldimethylethylammonium bromide, a cationic surfactant has been used to decolorize eriochromeazurol B, an anionic triphenylmethane type of dye. Addition of specific lanthanide metal ion to this decolorized solution resulted into intense colored stable ternary complex with large bathochromic shift from $540 \mathrm{~nm}$ (binary complex) to $650 \mathrm{~nm}$ (ternary complex) with increase in absorbance values at shifted wavelength. CDMEAB thus decreases the color intensity of ECAB and increases the absorbance value of ternary complexes. This two fold advantage resulted into enhancement in molar absorptivities and sensitivities at shifted wavelength of ternary complexes with stoichiometric composition $1:(1: 3)_{2},[\mathrm{Ln}:(\mathrm{R}: \mathrm{S})]$ for all lanthanides understudy namely yttrium, neodymium, europium, terbium and ytterbium. The ternary complexes at $\mathrm{pH} 6.0$ exhibited absorption maxima at $650 \mathrm{~nm}$ with molar absorptivities $69000 \mathrm{~L} \cdot \mathrm{mol}^{-1} \cdot \mathrm{cm}^{-2}$ for Y(III), $66000 \mathrm{~L} \cdot \mathrm{mol}^{-1} \cdot \mathrm{cm}^{-2}$ for $\mathrm{Nd}(\mathrm{III})$, $69000 \mathrm{~L} \cdot \mathrm{mol}^{-1} \cdot \mathrm{cm}^{-2}$ for $\mathrm{Eu}(\mathrm{III}), 64000 \mathrm{~L} \cdot \mathrm{mol}^{-1} \cdot \mathrm{cm}^{-2}$ for Tb(III), $70000 \mathrm{~L} \cdot \mathrm{mol}^{-}$ ${ }^{1} . \mathrm{cm}^{-2}$ for $\mathrm{Yb}(\mathrm{III})$. Beer's law were obeyed in concentration range 0.11-0.94, 0.19-1.53, 0.2-1.41, 0.21-1.69 and 0.23-1.11 ppm for Y(III), Nd(III), Eu(III), $\mathrm{Tb}(\mathrm{III})$ and $\mathrm{Yb}(\mathrm{III})$ respectively. Conditional formation constants and various analytical parameters have been evaluated and compared the results of newly formed ternary complexes with binary complexes. Finally newly suggested modified method have been recommended for the microdetermination of lanthanides understudy.
\end{abstract}

Keywords: Spectrophotometry, Eriochromeazurol B (ECAB), Cetyldimethylethylammonium bromide (CDMEAB), Europium (Eu), Neodymium (Nd), Terbium (Tb), Yttrium (Y), Ytterbium ( $\mathrm{Yb}$ ). 


\section{Introduction}

The lanthanide metal ions have found an ever increasing use in many areas of research such as synthesis, co-ordination chemistry, material science, photonic devices, catalysis etc. The metals like europium and yttrium are used in the production of red phosphor that is found in all color television screens. Yttrium is also used in heating elements alloys, super alloys and high temperature semiconductors. Ytterbium can be alloyed with stainless steel to improve some mechanical properties in fiber optic cables where it can be used as an amplifier and doping agent. Terbium is used in X-ray machines and green phosphor activator. Neodymium appears in many electronics such as fluorescent lights and color televisions.

Organic reagents play very important role in analytical and complex chemistry of lanthanides for its determination. With increasing demand of more sensitive reagents for their use in determination of metal ions by spectrophotometric technique, the attempts have been made in the past to intensify the color using third component like surfactant by converting the binary complex of lanthanides to ternary complex. It was observed that the addition of surfactant to dye solution decreases the color intensity of the reagent. The addition of specific metal ion to this decolorized solution resulted into the formation of intense colored stable ternary complexes with bathochromic shift in the wavelength with heightened molar absorptivity and sensitivity which primarily decides the usefulness and importance of the reagents developed for spectrophotometric determination of metal ions.

Very few ternary or mixed ligand complexes appear in the literature for their spectrophotometric microdeterminations. The ternary complexes of gallium (III) and lead (II) were reported with pyrocatechol violet in presence of some cationic surfactants ${ }^{1}$. Shokrollahi A. reported a spectrophotometric method for determination of sub-micro-molar amounts of aluminium (III) ion with eriochromecyanine $R$ in presence of DTAB as surfactant ${ }^{2}$. Spectrophotometric determination of scandium (III) in monazite after separation in presence of reagent eriochromecyanine $\mathrm{R}$ and surfactant CTAB have been reported by Chan-il-park and coworkers ${ }^{3}$. Application of chromeazurol $\mathrm{S}$ and benzyldodecyldimethylammonium bromide for gallium (III) determination in mineral fertilizers have been studied by Buhl F. and coworkers ${ }^{4}$. Spectrophotometric determination of uranium (VI) with pyrocatechol violet in cetyltrimethylammonium bromide and thorium (IV) and uranium (VI) with methyl thymol blue in presence of cetyldiethylammonium bromide have been reported earlier ${ }^{5-6}$.

Attempts have been made by using cationic surfactants like cetyltrimethylammonium bromide and cetylpyridinium bromide to improve the photometric sensitivity for the microdetermination of some lanthanides using some organic dyes ${ }^{7-12}$. The ternary association of chromeazurol $\mathrm{S}$ and cetyltrimethylammonium ion in presence of triton-100 was useful for the sensitive spectrophotometric determination of lanthanide in mixtures and in hydroxide concentrates as reported by Preisler et al ${ }^{13}$. Spectrophotometric study of ternary complex forming systems of dysprosium (III) and holmium (III) with pyrogallol red and some lanthanide metal ions with eriochromecyanine $\mathrm{R}$ in presence of cetylpyridinium bromide for microdetermination have been reported by A. S. Dhepe and A. B. Zade ${ }^{14,15}$. Magda Ali Akl et al have discussed the extraction, preconcentration and determination of microamounts of lanthanum and yttrium using alizarin red sulfonate (ARS) of a metal complex via surfactant-mediated phase separation ${ }^{16}$. The ternary interaction of naphthochrome green (NCG) with cetyltrimethylammonium bromide (CTAB) and lanthanides (Res: $\mathrm{Yb}$, Dy, Er and $\mathrm{Eu}$ ) has been investigated with the microsurface adsorption spectral correction technique (MSASC) ${ }^{17}$. The surfactant (CPB) sensitized analytical reaction of cerium (IV) with some triphenylformazan derivatives was studied by Ahmed and his coworkers ${ }^{18}$. 
The present investigation describes the systematic study on the use of eriochromeazurol $\mathrm{B}(\mathrm{ECAB})$ as spectrophotometric reagent for the microdetermination of lanthanides i.e. yttrium (III), neodymium (III), europium (III), terbium (III) and ytterbium (III) in absence as a binary complex and in presence of cationic surfactant cetyldimethylethylammonium bromide (CDMEAB) as a ternary complex and has not been reported so far.

\section{Experimental}

Instrumentation and reagent solutions

All the chemicals used were of analytical grade purity. Eriochromeazurol-B used was supplied by Sigma Chemical Company, U.S.A. and cetyldimethylethylammonium bromide (CDMEAB) by Aldrich Chemical Company, U.S.A. and its purity was estimated by argentometric titration for the determination of bromide ion content ${ }^{19}$. All the lanthanide oxides used were supplied by Indian Rare Earth Ltd., India, of 99.9\% purity. The stock solutions of lanthanides, CDMEAB and ECAB were prepared of strength $1.0 \times 10^{-3} \mathrm{M}$ and subsequently diluted with double distilled water.

The CDMEAB solution was first added to ECAB solution and was kept for half an hour. The metal ion solution was then added to dye-surfactant solution and again kept for half an hour to reach complete equilibrium. This order of mixing of solutions was maintained. Standard $\mathrm{HCl}$ and $\mathrm{NaOH}$ solutions were used for adjustment of $\mathrm{pH}$ of desired concentration. Beckman model B spectrophotometer was used for the measurement of absorbance with glass cuvettes of light path $10 \mathrm{~mm}$. All the experiments have been carried out at room temperature of $30 \pm 2^{0} \mathrm{C}$.

\section{Result and Discussion}

\section{Absorption spectra}

It has been considered necessary to have prior information on the nature of interaction between anionic ECAB and cationic CDMEAB before evaluating the ECAB as a sensitive reagent for the estimation of lanthanides in presence of CDMEAB. Therefore absorption spectra of $\mathrm{ECAB}$ in absence and presence of $\mathrm{CDMEAB}$, composition of dye-surfactant complex, absorption spectra of lanthanide complexes in absence and presence of CDMEAB, effect of $\mathrm{pH}$, composition and stability constants of the complexes in absence and presence of CDMEAB have been studied.

\section{Study of absorption spectra of ECAB in absence and presence of CDMEAB}

The color of ECAB has been found to be different at different $\mathrm{pH}$ values. Addition of CDMEAB brings about a change in color of ECAB at the same $\mathrm{pH}$ value. The absorption spectra of ECAB has been therefore, studied at different $\mathrm{pH}$ values (1.0 to 12.0) in absence and presence of $C D M E A B$. The wavelength of maximum absorbance of ECAB in absence and presence of CDMEAB are summarized in Table 1.

Absorption spectra of alkaline ECAB solution at $\mathrm{pH} 11.5$ show a characteristic maximum at $600 \mathrm{~nm}$. After the addition of CDMEAB, this maximum decreases and second absorption peak appears at 440nm. Visually this change represents a discoloration of the original pale violet solution to pale grayish or in more dilute solution to almost colorless.

Notable shifts are observed in the acidic medium. At $\mathrm{pH} 1.0, \lambda_{\max } 470 \mathrm{~nm}$ shifted to $520 \mathrm{~nm}$. In the $\mathrm{pH}$ range 2.0 to 4.0 peaks shifted from $490 \mathrm{~nm}$ to $520 \mathrm{~nm}$. There is no shifting of absorption maximum in the $\mathrm{pH}$ range 4.5 to 5.5. It has been observed that the absorbance value increases from $\mathrm{pH} 1.0$ to 5.0 and then decreases up to $\mathrm{pH} 12.0$. These 
changes in absorbance maximum in presence of CDMEAB may be attributed due to interaction between anionic $\mathrm{ECAB}$ and cationic $\mathrm{CDMEAB}$ might be resulting into the possible formation of so called "Dye-Surfactant complex".

Table 1. Wavelengths of maximum absorbance of ECAB in absence and presence of CDMEAB.

\begin{tabular}{cccc}
\hline & ECAB & \multicolumn{2}{c}{ ECAB+CDMEAB } \\
\hline $\mathrm{pH}$ & $\lambda_{\max }(\mathrm{nm})$ & $\mathrm{pH}$ & $\lambda_{\max }(\mathrm{nm})$ \\
\hline 1.0 & 470 & 1.0 & 520 \\
$2.0,3.0$ & 490 & $2.9,6.0$ & 520 \\
4.0 & 490 & 4.0 & 520 \\
$4.5,5.0,5.5$ & 510 & $4.5,5.0,5.5$ & 510 \\
$6.0,6.5,7.0$ & 430,600 & $6.0,6.5,7.0$ & 440 \\
$8.0,9.0,10.0,11.0$, & 420,600 & $8.0,9.0,10.0,11.0$, & 440 \\
12.0 & & 12.0 & \\
\end{tabular}

\section{Composition of ECAB-CDMEAB Complex}

The effect of varying CDMEAB concentration on the absorbance of ECAB has been studied in acidic medium at $\mathrm{pH} 6.0$ and alkaline medium at $\mathrm{pH} 11.5$ at $\lambda_{\max } 600 \mathrm{~nm}$ where the maximum discoloration has been observed. The absorbance of different concentrations of ECAB solution is plotted against variable concentration of CDMEAB. The concentration of ECAB taken were $2.0 \times 10^{-5} \mathrm{M}, 1.6 \times 10^{-5} \mathrm{M}$ and $1.33 \times 10^{-5} \mathrm{M}$ and have been represented by curve $\mathrm{A}, \mathrm{B}$ and $\mathrm{C}$ respectively in Figures 1 and 2 . It is observed that the maximum decolorizing effect reached at the minimal ECAB: CDMEAB ratio of 1:3. When this ratio was reach the absorbance of the reagent remains unaltered even when excess of five times of CDMEAB has been added. The modified reagent species thus formed may therefore be written as [ECAB (CDMEAB $\left.)_{3}\right]$.

The anionic $\mathrm{ECAB}$ dye and cationic surfactant reaction may be anionic in nature forming a new ECAB surfactant complex. This newly formed complex is useful for further microdetermination of metal ions.

$$
\mathrm{ECAB}^{-}-\mathrm{H}^{+}+\mathrm{CDMEA}^{+}-\mathrm{B}^{-} \rightleftharpoons \mathrm{ECAB}-\mathrm{CDMEA}+\mathrm{HBr} .
$$

\section{Absorption spectra of lanthanide complexes in absence and presence of surfactant}

Series of solutions were prepared by keeping the ratio of Metal: ECAB: CDMEAB as 1:1:10 and $4: 1: 10$. Number of sets was prepared for each ratio and $\mathrm{pH}$ was adjusted to 3.0, 3.5, 4.0, 5.0, 5.5, 6.0 and 6.5. The absorption spectra were recorded in the entire visible region from 400 to $700 \mathrm{~nm}$. Absorbance maxima of ECAB and its complexes with lanthanide in absence and presence of CDMEAB have been summarized at different $\mathrm{pH}$ values in Table 2. 


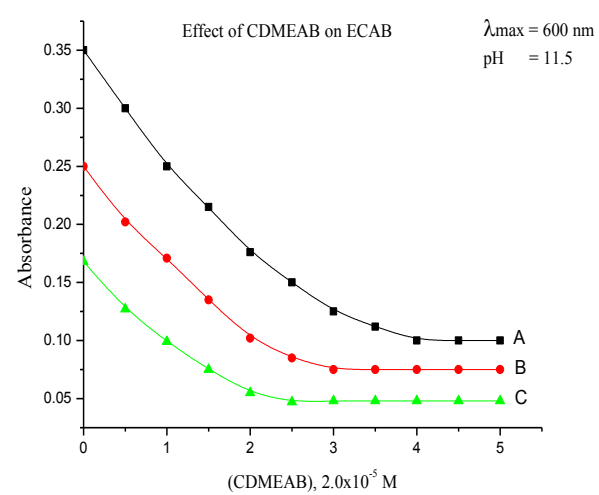

Figure 1. Effect of CDMEAB on ECAB in alkaline medium.

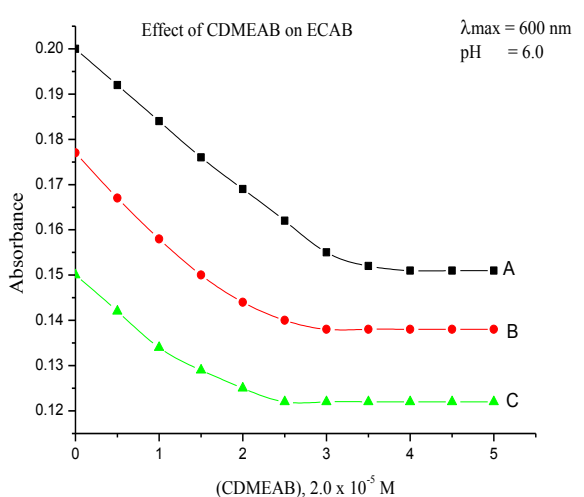

Figure 2. Effect of $\mathrm{CDMEAB}$ on $\mathrm{ECAB}$ in acidic medium.

Table 2. Absorbance maxima $(\mathrm{nm})$ of ECAB and its complexes in absence and presence of CDMEAB at different $\mathrm{pH}$.

\begin{tabular}{lcccccccc}
\hline System & 3.0 & 3.5 & 4.0 & 4.5 & 5.0 & 5.5 & 6.0 & 6.5 \\
\hline ECAB & 490 & 490 & 490 & 510 & 510 & 510 & 430 & 430 \\
ECAB + CDMEAB & 520 & 520 & 520 & 520 & 520 & 520 & 440 & 440 \\
ECAB + Y & 500 & 500 & 540 & 540 & 540 & 540 & 540 & 540 \\
ECAB + CDMEAB +Y & 530 & 530 & 550 & 650 & 650 & 650 & 650 & 650 \\
ECAB + Nd & 500 & 500 & 540 & 540 & 540 & 540 & 540 & 540 \\
ECAB + CDMEAB + Nd & 530 & 530 & 550 & 650 & 650 & 650 & 650 & 650 \\
ECAB + Eu & 500 & 500 & 540 & 540 & 540 & 540 & 540 & 540 \\
ECAB + CDMEAB +Eu & 530 & 530 & 540 & 650 & 650 & 650 & 650 & 650 \\
ECAB + Tb & 500 & 500 & 540 & 540 & 540 & 540 & 540 & 540 \\
ECAB + CDMEAB + Tb & 530 & 530 & 540 & 650 & 650 & 650 & 650 & 650 \\
ECAB + Yb & 500 & 500 & 540 & 540 & 540 & 540 & 540 & 540 \\
ECAB + CDMEAB + Yb & 530 & 530 & 540 & 650 & 650 & 650 & 650 & 650 \\
\hline
\end{tabular}

In the $\mathrm{pH}$ range 3.0 to 3.5 in absence and presence of CDMEAB, the wavelength maxima of ECAB shows small change in $\lambda_{\max }$ and absorbance values; indicating poor complexation. However in presence of CDMEAB only one sharp peak has been observed at $650 \mathrm{~nm}$ in the $\mathrm{pH}$ range 4.5 to 6.5 with high absorbance values. It has been observed that the maximum complexation takes place at $\mathrm{pH} 6.0$ by comparing the absorption spectra and the absorbance values of the reagent and complex in absence and presence of CDMEAB as reported in the Table 2. But broad peak is observed in $\mathrm{pH}$ range 4.0 to 6.0 in the wavelength region around $540 \mathrm{~nm}$ indicating weak complexation in absence of CDMEAB for all lanthanides. 
In Figure 3 to 7, the metal ions Eu (III), Nd (III), Tb (III), Y (III) and $\mathrm{Yb}$ (III) indicates binary complexation with $\mathrm{ECAB}$ and ternary with $\mathrm{ECAB}$ and CDMEAB at $\mathrm{pH}$ 6.0. Curve $\mathrm{D}$ represents the absorption spectra of $\mathrm{ECAB}$ alone at $\mathrm{pH} 6.0$ showing a peak at $430 \mathrm{~nm}$ and second peak was also observed at $600 \mathrm{~nm}$. ECAB in presence of CDMEAB has been indicated by curve $\mathrm{C}$ showing the $\lambda_{\max }$ at $440 \mathrm{~nm}$ (single peak). Curve B indicates a broad peak around $540 \mathrm{~nm}$ indicating weak complexation. Thus shifting in $\lambda_{\max }$ from 430 to 540 $\mathrm{nm}$ in absence for binary and from 440 to $650 \mathrm{~nm}$ in presence of CDMEAB for ternary have been observed indicating a bathochromic shift of $110 \mathrm{~nm}$ in absence and $210 \mathrm{~nm}$ in presence of CDMEAB for all lanthanides.

Thus the complex formation of lanthanides in presence of CDMEAB shows large bathochromic shift and increased absorbance value causing marked sensitization of above color reaction resulting into high molar absorptivity of ternary complex which may be applied as useful tool in microdetermination of metal ions understudy.

\section{Effect of $p H$}

In Figure 8 variation of $\lambda_{\max }$ of europium complex at different $\mathrm{pH}$ value was studied in absence and presence of ten fold excess of CDMEAB. Curve A represents variation of $\lambda_{\max }$ with change in $\mathrm{pH}$ of solution of ECAB in absence of CDMEAB. It shows $\lambda_{\max }$ at $510 \mathrm{~nm}$ in $\mathrm{pH}$ range $4.5-5.5$ and suddenly decreases to $430 \mathrm{~nm}$ from where it remains constant upto 6.5. Curve $B$ represents variation of $\lambda_{\max }$ with change in $\mathrm{pH}$ of the solution of ECAB in presence of CDMEAB show the constant $\lambda_{\max }$ at $520 \mathrm{~nm}$ in the $\mathrm{pH}$ range 4.0 to 5.5 which then shifted at $440 \mathrm{~nm}$ and remains constant upto $\mathrm{pH}$ 6.5. Curve $\mathrm{C}$ represent the variation of $\lambda_{\max }$ with change in $\mathrm{pH}$ of Eu complex in absence of CDMEAB. The horizontal portion of curve $\mathrm{C}$ in figure shows that the $\lambda_{\max }$ of binary complex remains constant in the $\mathrm{pH}$ range 4.0 to 6.5 indicating $\mathrm{pH}$ range of stability of constant wavelength of the complexes. Curve $\mathrm{D}$ represents variation of $\lambda_{\max }$ with change in $\mathrm{pH}$ of complexes of europium metal ion in presence of CDMEAB and indicate that the $\lambda_{\max }$ of ternary complex remains constant in the $\mathrm{pH}$ range 4.5 to 6.5 i.e $\mathrm{pH}$ range of stability of constant wavelength.

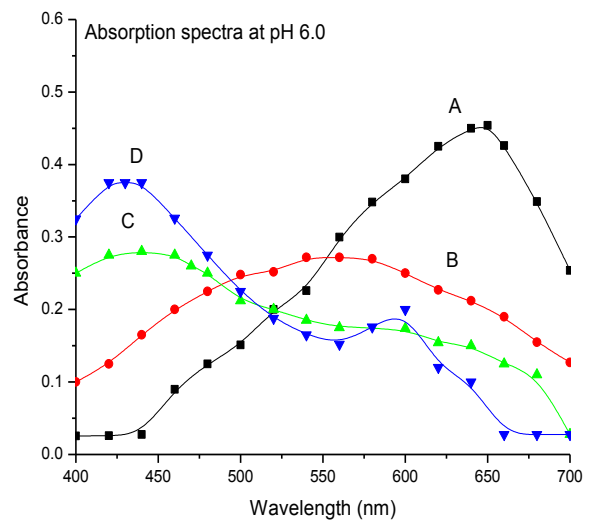

Figure 3. Absorption spectra of $\mathrm{Eu}$ at $\mathrm{pH}$ 6.0, A-ECAB-CDMEAB-Eu-(Ternary complex). B-ECAB-Eu at(pH 6.0)-(Binary complex), C-ECAB-CDMEAB-(Modified reagent), D-ECAB-(Reagent).

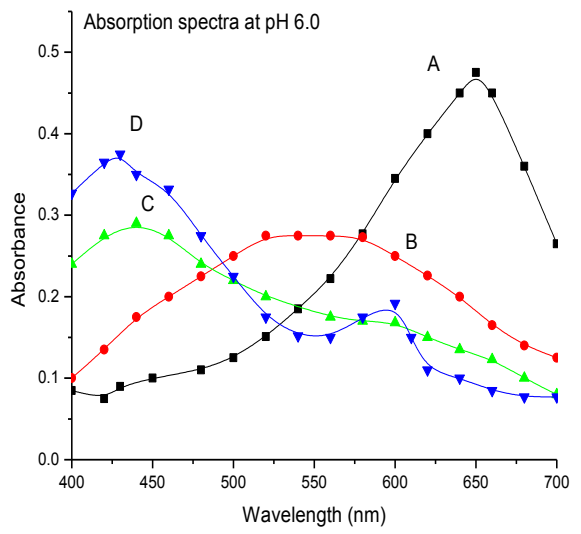

Figure 4. Absorption spectra of $\mathrm{Nd}$ at $\mathrm{pH}$ 6.0, A-ECAB-CDMEAB-Nd-(Ternary complex). B-ECAB-Nd at(pH 6.0)-(Binary complex), C-ECAB-CDMEAB-(Modified reagent), D-ECAB-(Reagent). 


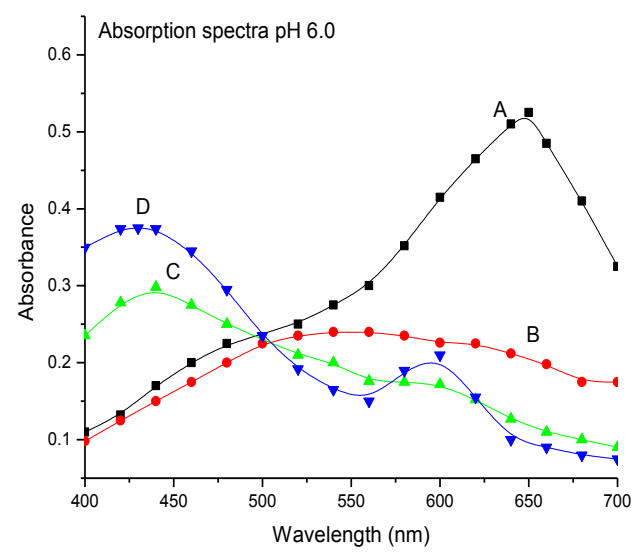

Figure 5. Absorption spectra of $\mathrm{Tb}$ at $\mathrm{pH} \mathrm{6.0,}$ A-ECAB-CDMEAB-Tb-(Ternary complex). B-ECAB-Tb at(pH 6.0)-(Binary complex), CECAB-CDMEAB-(Modified reagent), DECAB-(Reagent).

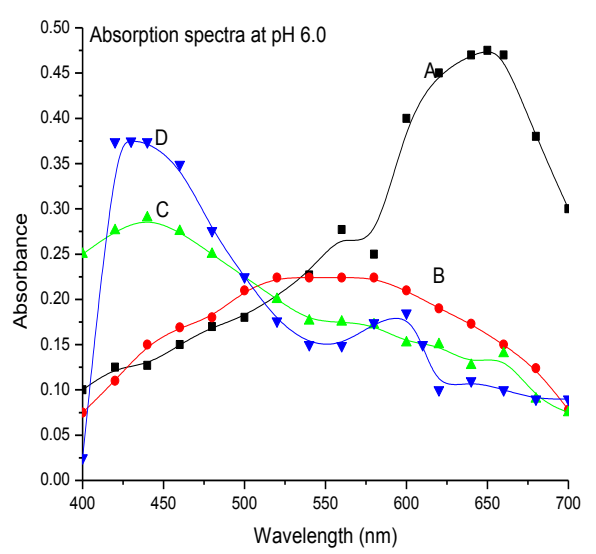

Figure 6. Absorption spectra of $\mathrm{Y}$ at $\mathrm{pH}$ 6.0, A-ECAB-CDMEAB-Y-(Ternary complex). B-ECAB-Y at(pH 6.0)-(Binary complex), C-ECAB-CDMEAB-(Modified reagent), D-ECAB-(Reagent) .

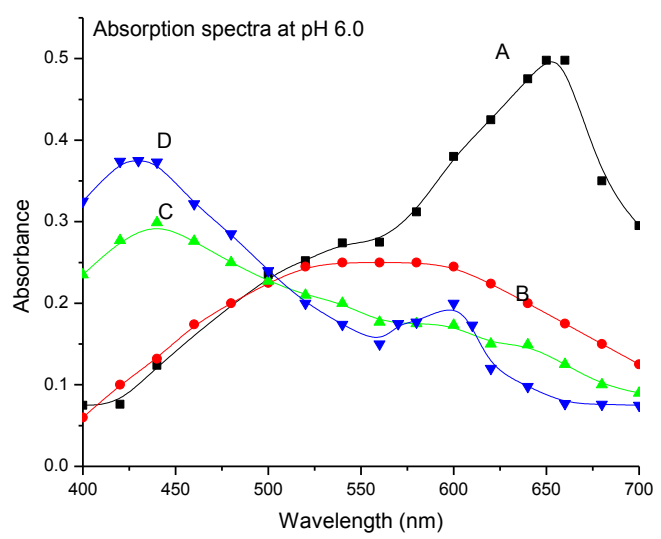

Figure 7. Absorption spectra of $\mathrm{Yb}$ at $\mathrm{pH}$ 6.0, A-ECAB-CDMEABYb-(Ternary complex). B-ECAB-Yb at ( $\mathrm{pH}$ 6.0)-(Binary complex), C-ECAB-CDMEAB-(Modified reagent), D-ECAB-(Reagent).

In figure 9 Curve $\mathrm{B}$ represents the plot of absorbance of Eu complex of ECAB at the wavelength of maximum absorbance i.e. $650 \mathrm{~nm}$ in presence of CDMEAB with the changes in $\mathrm{pH}$ in the range 4.0-6.5. The curves clearly shows that the absorbance increases almost linearly in the $\mathrm{pH}$ range 4.0-5.5, however it attains the maximum value at 5.5 and remain constant upto $\mathrm{pH} 6.5$ as indicated by straight line portion of the curves. This $\mathrm{pH}$ range where the absorbance of the complex at the $\lambda_{\max }$ is termed as optimum $\mathrm{pH}$ range of stability of complex formation. Curve A represents the plot of absorbance of lanthanide complexes at 
$540 \mathrm{~nm}$ in absence with changes in $\mathrm{pH}$ in the range 4.0 to 6.5. The curves in Figure 9 show range $6.0-6.5$ as optimum $\mathrm{pH}$ range of constant absorbance.

The $\mathrm{pH}$ range of stability and optimum $\mathrm{pH}$ range of stability of all the lanthanide complexes of ECAB in absence and presence of CDMEAB understudy are recorded in Table 3.

Table 3. $\mathrm{pH}$ range of stability of ECAB complexes in absence and presence of CDMEAB.

\begin{tabular}{ccccccr}
\hline $\begin{array}{l}\text { lanthanide } \\
\text { complexes }\end{array}$ & $\lambda_{\max }$ of ECAB $(\mathrm{nm})$ & \multicolumn{2}{c}{$\begin{array}{c}\text { pH range of } \\
\text { stability of constant } \\
\text { wavelength }\end{array}$} & \multicolumn{2}{c}{$\begin{array}{c}\text { pH range of stability } \\
\text { of constant } \\
\text { absorbance }\end{array}$} \\
\hline & Absence & Presence & Absence & Presence & Absence & Presence \\
\hline $\mathrm{Y}(\mathrm{III})$ & 540 & 650 & $4.0-6.5$ & $4.5-6.5$ & $6.0-6.5$ & $5.5-6.5$ \\
$\mathrm{Nd}(\mathrm{III})$ & 540 & 650 & $4.0-6.5$ & $4.5-6.5$ & $6.0-6.5$ & $5.5-6.5$ \\
$\mathrm{Eu}(\mathrm{III})$ & 540 & 650 & $4.0-6.5$ & $4.5-6.5$ & $6.0-6.5$ & $5.5-6.5$ \\
$\mathrm{~Tb}(\mathrm{III})$ & 540 & 650 & $4.0-6.5$ & $4.5-6.5$ & $6.0-6.5$ & $5.5-6.5$ \\
$\mathrm{Yb}(\mathrm{III})$ & 540 & 650 & $4.0-6.5$ & $4.5-6.5$ & $6.0-6.5$ & $5.5-6.5$ \\
\hline
\end{tabular}

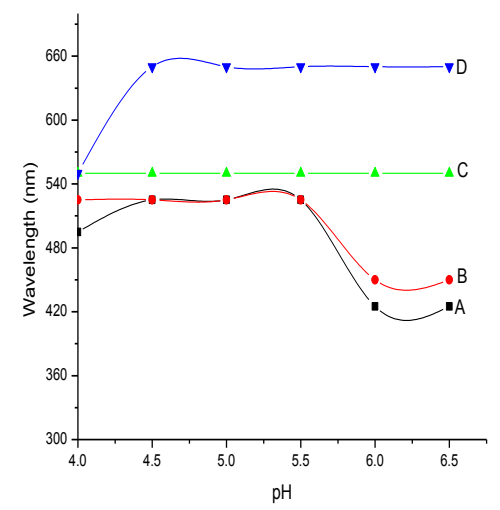

Figure 8. Variation in $\lambda_{\max }$ with change in the pH of: A [ECAB]-(Reagent), B

[ECAB+CDMEAB]-(Modified reagent), $\mathrm{C}$ [ECAB+Eu(III)-(Binary complex), D $[\mathrm{ECAB}+\mathrm{CDMEAB}+\mathrm{Eu}(\mathrm{III})$ - (Ternary complex).

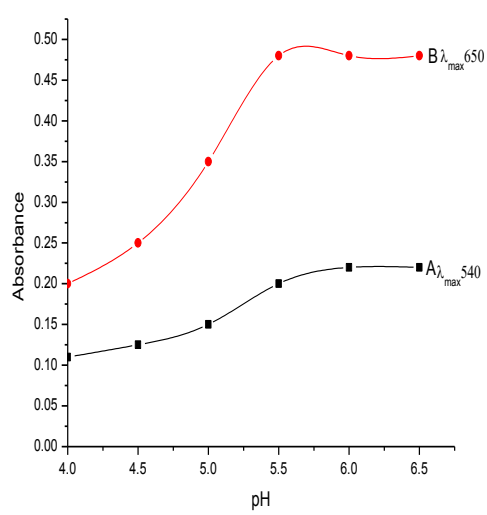

Figure 9. Variation in absorbance at the $\lambda_{\max }$ with change in the $\mathrm{pH}$ of :
A- $\lambda_{\max }, 540 \mathrm{~nm}$ of ECAB-Eu (Binary complex)
B- $\lambda_{\max }, 650 \mathrm{~nm}$ of ECAB-CDMEAB- $\mathrm{Eu}$ (Ternary complex).

\section{Composition of Complexes}

Quantitative information on complex formation is obtained by determining its composition and stability constants of complexes formed. From the spectral studies, it has been found that the reagent ECAB forms only one type of complex with lanthanide metal ions understudy. The composition of complexes has been studied by the Job's method of continuous variation ${ }^{20}$ and it has been further confirmed by Mole ratio method. For Job's 
method, solutions of lanthanide and ECAB have been taken in three equimolar concentrations of $2.5 \times 10^{-4} \mathrm{M}, 2 \times 10^{-4} \mathrm{M}$, and $1.66 \times \times 10^{-4} \mathrm{M}$; five times excess of CDMEAB has been then added for studying the composition in presence of surfactant.

The stoichiometric composition between the metal ion and ECAB in presence and absence of $C D M E A B$ has been found to be 1:2. It has been observed that $\mathrm{ECAB}$ reagent at $\mathrm{pH} 6.0$ exists as $\left[\mathrm{ECAB}(\mathrm{CDMEAB})_{3}\right]_{\text {and }}$ therefore the composition of complexes in presence of $\mathrm{CDMEAB}$ may be written as $\operatorname{Ln}\left[\mathrm{ECAB}(\mathrm{CDMEAB})_{3}\right]_{2}$ for all lanthanide complexes. The composition has been further confirmed by Mole ratio method. This is just a tentative reaction and further studies in this regard is necessary for confirmation of the composition as the emphasis has been given in the present investigation on microdetermination of metal ions in presence of CDMEAB. The formation of complexes may therefore be expressed by equation (omitting charges).

$$
\begin{aligned}
\mathrm{ECAB}+3 \mathrm{CDMEAB} & \rightleftharpoons \operatorname{ECAB}(\mathrm{CDMEAB})_{3} \\
\mathrm{M}+2\left[\mathrm{ECAB}(\mathrm{CDMEAB})_{3}\right] & \rightleftharpoons \mathrm{M}\left[\mathrm{ECAB}(\mathrm{CDMEAB})_{3}\right]_{2}
\end{aligned}
$$

Table 4. Composition and $\log \mathrm{K}$ values of lanthanide complexes of ECAB in absence and

\begin{tabular}{|c|c|c|c|c|}
\hline $\begin{array}{l}\text { Complexes } \\
\text { of ECAB }\end{array}$ & $\begin{array}{l}\mathrm{pH} \text { of } \\
\text { study }\end{array}$ & $\begin{array}{l}\text { Wavelength } \\
\text { of study, nm }\end{array}$ & $\begin{array}{l}\text { Composition Ln : R, } \\
\text { Ln : (R:S) }\end{array}$ & $\begin{array}{c}\text { Log K values by Job's } \\
\text { method }\end{array}$ \\
\hline Y(III) & $\begin{array}{l}\text { A } 6.0 \\
\text { P } 6.0\end{array}$ & $\begin{array}{l}540 \\
650\end{array}$ & $\begin{array}{c}1: 2 \\
1:(1: 3)_{2}\end{array}$ & $\begin{array}{l}10.19 \\
10.46\end{array}$ \\
\hline $\mathrm{Nd}(\mathrm{III})$ & $\begin{array}{l}\text { A } 6.0 \\
\text { P } 6.0\end{array}$ & $\begin{array}{l}540 \\
650\end{array}$ & $\begin{array}{c}1: 2 \\
1:(1: 3)_{2}\end{array}$ & $\begin{array}{c}9.55 \\
10.91\end{array}$ \\
\hline $\mathrm{Eu}(\mathrm{III})$ & $\begin{array}{l}\text { A } 6.0 \\
\text { P } 6.0\end{array}$ & $\begin{array}{l}540 \\
650\end{array}$ & $\begin{array}{c}1: 2 \\
1:(1: 3)_{2}\end{array}$ & $\begin{array}{c}9.88 \\
10.91\end{array}$ \\
\hline $\mathrm{Tb}(\mathrm{III})$ & $\begin{array}{l}\text { A } 6.0 \\
\text { P } 6.0\end{array}$ & $\begin{array}{l}540 \\
650\end{array}$ & $\begin{array}{c}1: 2 \\
1:(1: 3)_{2}\end{array}$ & $\begin{array}{c}9.88 \\
10.57\end{array}$ \\
\hline $\mathrm{Yb}(\mathrm{III})$ & $\begin{array}{l}\text { A } 6.0 \\
\text { P } 6.0\end{array}$ & $\begin{array}{l}540 \\
650\end{array}$ & $\begin{array}{c}1: 2 \\
1:(1: 3)_{2}\end{array}$ & $\begin{array}{l}10.08 \\
10.43\end{array}$ \\
\hline
\end{tabular}
presence of CDMEAB.

A: Absence, P: Presence. 


\section{Stability Constant}

Values of $\log \mathrm{K}$ of complexes of lanthanides understudy in absence and presence of CDMEAB have been calculated from Job's method ${ }^{20}$ are reported in Table 4. The result shows that the value of $\log \mathrm{K}$ for particular metal ion in presence of CDMEAB is greater than in absence of CDMEAB. This increase in $\log \mathrm{K}$ values in presence of CDMEAB is due to formation of stable complexes.

\section{Analytical Applications of Ternary Complexes of Lanthanides (in Presence of CDMEAB)}

The large shift of $110 \mathrm{~nm}$ in absorption maxima of the complex from $540 \mathrm{~nm}$ in absence to $650 \mathrm{~nm}$ in presence of CDMEAB at $\mathrm{pH} 6.0$ where the absorption of reagent is comparatively negligible and facilitate the analytical measurements making the reagent very sensitive for particular color reaction.

\section{Order of addition of reactants}

Sequence of addition of reactants must be followed strictly. In all the experiments, CDMEAB was first added to ECAB solution of desired concentration. This solution was kept for at least 30 minutes for equilibration. To this solution of modified ECAB, the metal ion solution was then added which again kept for 30 minutes for complete formation of ternary complex.

\section{Rate of color formation and stability of color at room temperature}

The color formation does not depend on reaction time and is almost instantaneous in presence of CDMEAB. However the mixtures were kept for 30 minutes for equilibration. A mixture containing $2.5 \times 10^{-4} \mathrm{M}$ ECAB, $1.0 \times 10^{-4} \mathrm{M}$ ECAB, and $2.5 \times 10^{-4} \mathrm{M}$ lanthanide solutions at $\mathrm{pH} 6.0$ retained its absorbance value even after 24 hours standing at room temperature. The temperature was found to have no effect on color intensity of ternary complexes from $20^{\circ} \mathrm{C}$ to $60^{\circ} \mathrm{C}$.

\section{Effect of reagent concentration}

Different volumes of $1.0 \times 10^{-4} \mathrm{M}$ of ECAB were taken in different flasks to which equal volume of $5.0 \times 10^{-4} \mathrm{M}$ CDMEAB was added. One $\mathrm{ml}$ of $1.0 \times 10^{-4} \mathrm{M}$ metal ions was then added in each flask. Total volume was maintained at $50 \mathrm{ml}$ at $\mathrm{pH} 6.0$. Absorbance readings were recorded at $650 \mathrm{~nm}$. It was found that ECAB in all the cases of metal ions understudy must be present at least two times more than metal ion to have maximum color development. However in absence of CDMEAB reagent needed was six times that of metal ion for full color development.

\section{Beer's Law and effective photometric ranges}

The linearity between the absorbance of complexes and concentration of metal ion has been tested by taking the different volumes of metal ion solution $\left(1.0 \times 10^{-3} \mathrm{M}\right.$ in absence and $6.66 \times 10^{-4} \mathrm{M}$ in presence of CDMEAB). The final concentration of ECAB taken was $2.0 \times$ $10^{-4} \mathrm{M}$, of CDMEAB was $1.0 \times 10^{-3} \mathrm{M}$. Total volume was kept constant at $50 \mathrm{ml}$ at $\mathrm{pH} 6.0$. The absorbance values were measured in absence of CDMEAB at $540 \mathrm{~nm}$. However in presence of CDMEAB all the spectral measurements were made at $650 \mathrm{~nm}$. The range of Beer's law is given in Table 4 in absence and presence of CDMEAB. The effective range for photometric determination was also calculated from these data by Ringbom plot ${ }^{21}$ (log of metal ion concentration versus percentage transmittance). Thus the range as derived by the slope of curve is selected to be range for the effective photometric determination as given in Table 5. 
Table 5. Photometric determination of lanthanides with ECAB in absence and presence of CDMEAB.

\begin{tabular}{ccccccc}
\hline $\begin{array}{c}\text { Complexes } \\
\text { of ECAB }\end{array}$ & $\begin{array}{c}\text { pH of } \\
\text { study }\end{array}$ & $\begin{array}{c}\text { Wavelength } \\
\text { of study, } \\
(\mathrm{nm})\end{array}$ & $\begin{array}{c}\text { Beer's law } \\
\text { Range } \\
\text { (ppm) }\end{array}$ & $\begin{array}{c}\text { Effective } \\
\text { Photome-tric } \\
\text { range } \\
\text { (ppm) }\end{array}$ & $\begin{array}{c}\text { Sendell's } \\
\text { sensitivity }\end{array}$ & $\begin{array}{c}\text { Molar } \\
\text { Absorpti- } \\
\text { vity }\end{array}$ \\
\hline \multirow{2}{*}{ Y(III) } & A 6.0 & 540 & $0.17-0.88$ & $0.35-0.71$ & 0.002 & 46000 \\
& P 6.0 & 650 & $0.11-0.94$ & $0.23-0.71$ & 0.0012 & 69000 \\
& A 6.0 & 540 & $0.28-1.44$ & $0.57-1.15$ & 0.003 & 37000 \\
Nd(III) & P 6.0 & 650 & $0.19-1.53$ & $1.15-2.69$ & 0.0021 & 66000 \\
& A 6.0 & 540 & $0.30-1.52$ & $0.608-1.82$ & 0.004 & 42000 \\
Eu(III) & P 6.0 & 650 & $0.2-1.41$ & $0.20-0.81$ & 0.0022 & 69000 \\
& A 6.0 & 540 & $0.31-1.90$ & $0.63-1.58$ & 0.0047 & 42000 \\
& P 6.0 & 650 & $0.21-1.69$ & $0.21-0.81$ & 0.0024 & 64000 \\
& A 6.0 & 540 & $0.31-1.73$ & $0.69-1.38$ & 0.0038 & 45000 \\
& P 6.0 & 650 & $0.23-1.11$ & $0.46-1.15$ & 0.0024 & 70000 \\
\hline
\end{tabular}

A: Absence, P: Presence.

\section{Sensitivities and Molar absorptivites}

Molar absorptivities of the complexes have been determined by taking a constant amount of $\mathrm{ECAB}$ and different amount of excess of metal ions and five times excess of CDMEAB at pH 6.0. The values of molar absorptivities and Sandell's sensitivities ${ }^{22}$ of metal complexes in absence and presence of CDMEAB at the wavelength of study are given in Table 5. The increase in values of sensitivities and molar absorptivities of the ternary complexes than binary complexes again shows the sensitization of reagent in presence of CDMEAB.

\section{Effect of Foreign ions}

The effect of foreign ions has been studied by taking 28.84 ug of $\mathrm{Nd}$ (III) and determining its concentration in presence of large number of interfering ions. The method suffers from lack of selectivity but the interferences are not too many. The determination is possible in absence of metal ions such as Ag (I), Pd (II), Hg (II), In (III), Au (III), Th (IV), U (VI) and some transition metal ions. Anions such as nitrates, oxalates, citrates, succinates and EDTA which strongly interfere.

\section{Procedure for Microdetermination}

Adjust the $\mathrm{pH}$ of solution containing 0.5 to $4.5 \mathrm{ppm}$ of lanthanide (III) metal ions to 6.0. Add about two fold excess of modified ECAB solution of same $\mathrm{pH}$ (The modified ECAB solution is prepared by adding about five fold excess of CDMEAB solution to ECAB solution and keeping it for at least 30 minutes for complete equilibration.) Dilute the solution to total volume of $50 \mathrm{ml}$ with distilled water. Allow the mixture to stand for 30 minutes for full color development and equilibration. Measure the absorbance of this unknown solution at $650 \mathrm{~nm}$ against reagent blank prepared in the same manner. Compare the absorbance of this unknown solution from the calibration curve obtained under similar conditions. Results of the determination of individual metal ions have been reported in the table 6 . 
Table 6. Determination of Individual Metal Ion.

\begin{tabular}{cccc}
\hline Lanthanides & $\begin{array}{c}\text { Amount taken } \\
\mu \mathrm{g} / 50 \mathrm{ml}\end{array}$ & $\begin{array}{c}\text { Amount found } \\
\mu \mathrm{g} / 50 \mathrm{ml}\end{array}$ & $\begin{array}{c}\text { Standard } \\
\text { average } \\
\text { deviation }\end{array}$ \\
\hline $\mathrm{Y}(\mathrm{III})$ & 35.56 & 35.50 & \pm 0.042 \\
$\mathrm{Nd}(\mathrm{III})$ & 25.84 & 25.97 & \pm 0.04 \\
$\mathrm{Eu}(\mathrm{III})$ & 30.40 & 30.45 & \pm 0.03 \\
$\mathrm{~Tb}(\mathrm{III})$ & 42.37 & 42.42 & \pm 0.03 \\
$\mathrm{Yb}(\mathrm{III})$ & 34.60 & 34.50 & \pm 0.04 \\
\hline
\end{tabular}

\section{Conclusion}

The spectrophotometeric determination of lanthanides with eriochromeazurol-B in absence and presence of cetyldimethylethylammonium bromide have been studied. Following are the merits of modified method.

1) The sensitization of $\mathrm{ECAB}$ by addition of $\mathrm{CDMEAB}$ is clear from the fact that formation of stable ternary complexes with lanthanides occurs at $\mathrm{pH} 6.0$ with bathochromic shift in the $\lambda_{\max }$ of metal ion-ECAB complexes in presence of cationic surfactant. This change is attributed due to formation of ternary complex system in presence of CDMEAB in acidic medium compared to the binary system in absence of CDMEAB.

2) The formation of stable ternary complexes with sharp peak in wider $\mathrm{pH}$ range as compared to weak binary complexes with broad shoulder in small $\mathrm{pH}$ range.

3) The increase in value of $\log \mathrm{K}$ in presence of CDMEAB for particular metal ion is greater than in absence of CDMEAB shows the formation of stable complexes.

4) Due to the shifted $\lambda_{\max }$ towards higher wavelength (From 540 to $650 \mathrm{~nm}$ ) and comparatively negligible absorbance of reagent gives the large difference in absorbance between the reagent blank (ECAB-CDMEAB) and its ternary complex which results in enhancement of sensitivities and molar absorptivities again indicates the sensitization of color reaction. In present investigation which was used for the determination of metal ions understudy when present in small concentration.

5) Further, the modified method requires smaller molar concentration of ECAB over the metal ion concentration for full color development and is instantaneous in presence of CDMEAB again indicates the stability of color reaction.

6) The modified reagent i.e. $\left[\mathrm{ECAB}(\mathrm{CDMEAB})_{3}\right]$ has also been found to be extremely useful in complexometric titration of lanthanide metal ions. This modified reagent act as sensitive metallochromic indicator giving a very sharp color change at the end point.

7) These observations suggest that a very useful application of these colored reactions in presence of ECAB or CDMEAB can be made in spectrophotometric determination of the metal ions with much enhanced sensitivity. It may be mentioned here that $\mathrm{ECAB}$ in presence of $\mathrm{CDMEAB}$ have been suggested for the first time as a sensitive reagents for spectrophotometric determination of metal ions understudy.

\section{Acknowledgement}

Authors are thankful to Prof. R. B. Mankar, Formar Director of Laxminarayan Institute of Technology, R.T.M. Nagpur University, Nagpur and presently Vice-Chancellor of Dr. 
Babasaheb Ambedkar Technical University, Lonere (MS) and Dr. M.K.N. Yenkie, Director In Charge, Laxminarayan Institute of Technology and Registrar of R.T.M. Nagpur University, Nagpur for constant encouragement and support.

\section{References}

1. Jarosz M, Microchem J, 1988, 37, 268.

2. Shokrollahi A, Ghaedi M, Niband M S and Rajabi H R, Journal of Hazardous Materials, 2008, 151(2-3), 642-648.

3. Chan- il Park and Ki-Won Chan, Bull. Korean Chem. Soc., 1999, 20(12).

4. Buhl Franciszek and Poledniok Justyna, Chemia analityczna, 2002, 47(1), 163-167.

5. Chan-il Park, Hua-Zi Huang and Ki Won Cha, Bull Korean chem. soc., 2001, 22(1), 84-86.

6. Upase A B and Zade A B, J. Indian Chem. Soc., 2005, 82, 853-856.

7. Svoboda V and Chromy V, Talanta, 1966, 13, 257.

8. Otomo M and Wakamatsu Y, Jap. Anal, 1968, 17, 764.

9. De wet M J and Behrens G B, Anal Chem, 1968, 40, 200.

10. Kirillow A S, Zh Anal Khim, 1973, 28, 1618.

11. Poluektov N S, Zh Anal Khim, 1974, 29, 1715.

12. Vekhande C R and. Munshi K N, Indian J. of Chem., Sect. A, 1976, 14, 189.

13. Preisler, Jan, Jancar, Ludek, Sommer, Lumir, Collection of Czechoslovak Chemical Communications, 2009, 58(7), 1495-1508.

14. Dhepe A S and Zade A B, J. Indian Chem. Soc., 2010, 9(2), 215-221.

15. Dhepe A S and Zade A B, E-journal of chem. 2010, 8(2), 000-0100.

16. Magda Ali Akl, Mohammed Abdel Ghany Kabil, Amin Mahmoud Abdallah and Dalia Salah Ismael, Bulletin of the Chemical Society of Japan, 2003,76 (8),15431547.

17. Chaudhary Govinda, Mohan Reddy K.P.P.R and Reddy Raveendra. Indian Journal of Chemistry A, 2008, 47, 1381.

18. Ahmed I S, Amin A S and Issa Y M, Spectrochimica Acta A, 2006, 64, 246.

19. Zade A B and Munshi K N Plenum Press New York, 1989, 9, 261.

20. Job P, Ann Chim., 9, 113 Chem. Abst. 1928, 22, 2120.

21. Ringbom A Z Anal Chem. 1939,115, 332.

22. Sandell E B Colorimetric determination of trace metals $3^{\text {rd }}$ Edition. Inter science Publishers Inc New York, 1959, 568. 


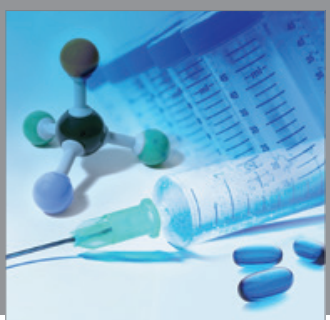

International Journal of

Medicinal Chemistry

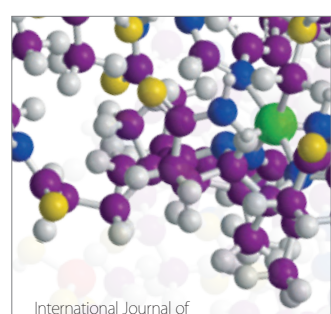

Carbohydrate Chemistry

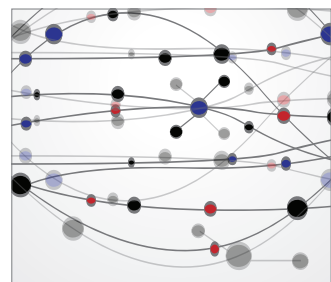

The Scientific World Journal
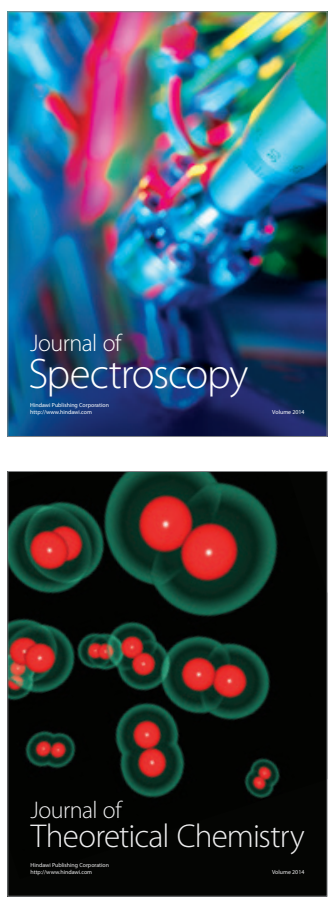
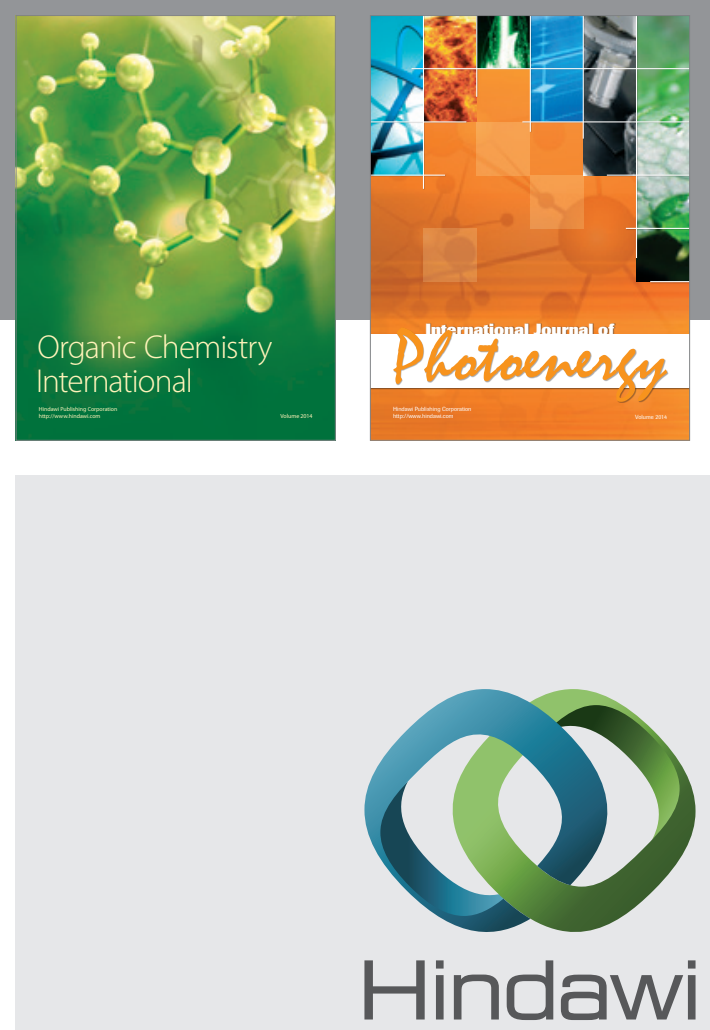

Submit your manuscripts at

http://www.hindawi.com
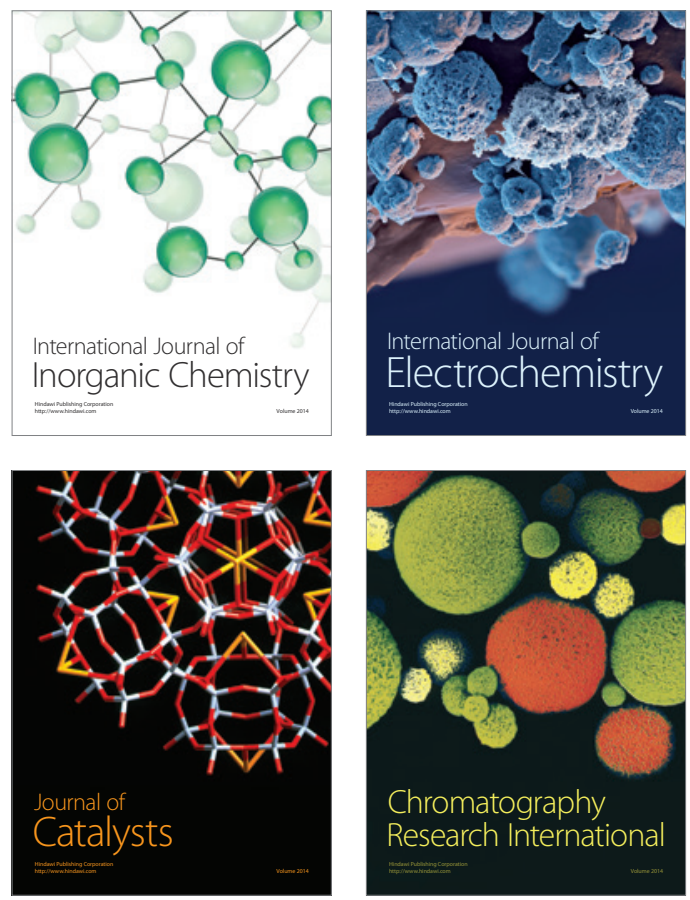
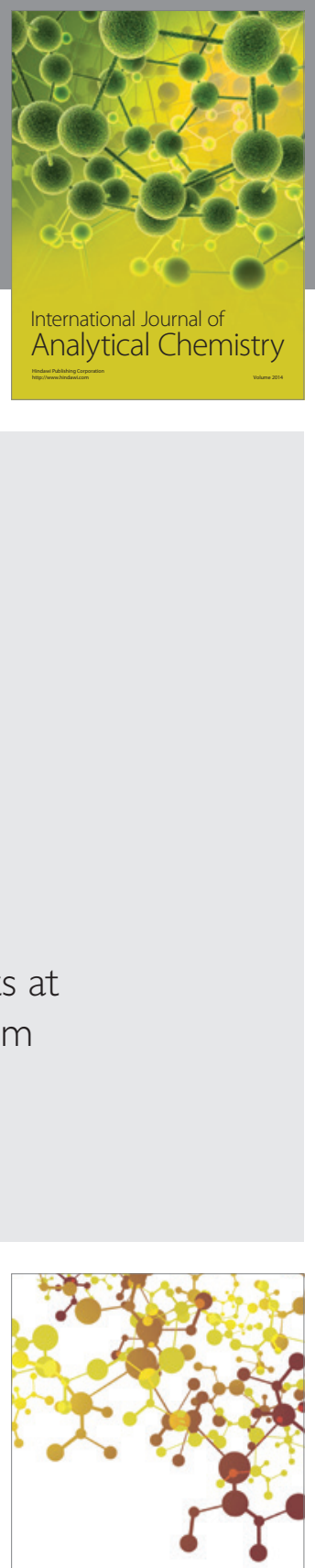

Journal of

Applied Chemistry
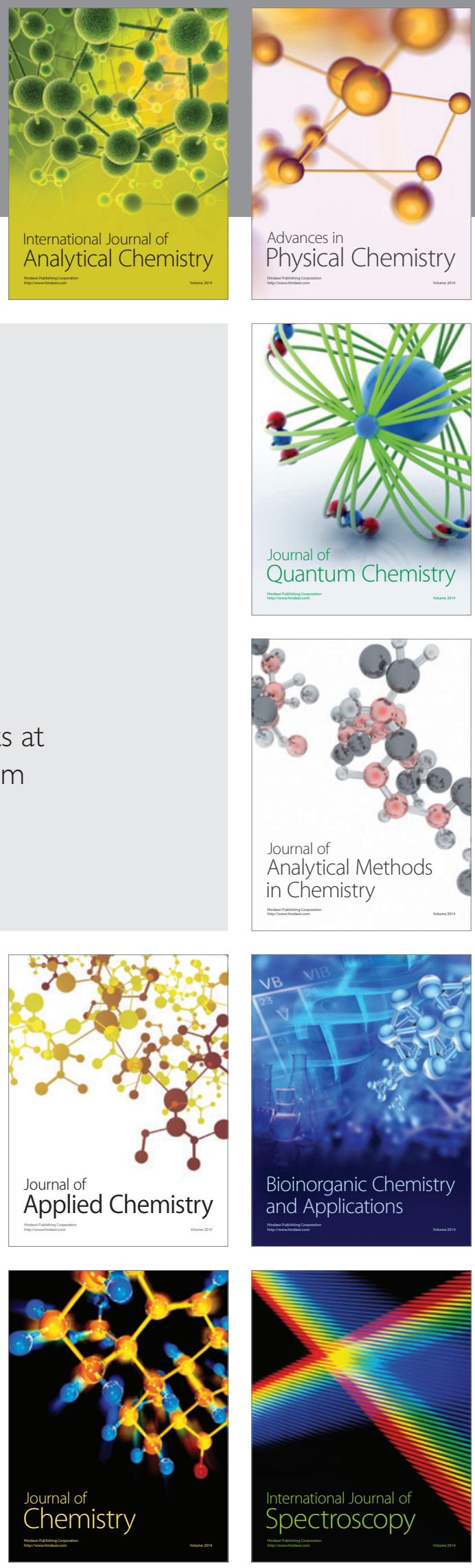